\title{
Correction to: Metabolic Enhancer Piracetam Attenuates the Translocation of Mitochondrion-Specific Proteins of Caspase Independent Pathway, Poly [ADP-ribose] Polymerase 1 Up-regulation and Oxidative DNA Fragmentation
}

\author{
Dinesh Kumar Verma ${ }^{1}$. Sonam Gupta ${ }^{1}$ Joyshree Biswas ${ }^{1} \cdot$ Neeraj Joshi $^{3} \cdot$ K. Sivarama Raju ${ }^{2}$ M. Wahazuddin ${ }^{2}$. \\ Sarika Singh ${ }^{1}$
}

Published online: 15 January 2022

(c) Springer Science+Business Media, LLC, part of Springer Nature 2022

\section{Correction to: Neurotox Res:}

https://doi.org/10.1007/s12640-018-9878-2

Inadvertent mistake had happened in Fig. 1. Please find the corrected figure here.

Fig. 1 Bright field images of N2A cells after LPS and/or LPS + piracetam (P-10 mM) treatment. Bar diagram illustrating the cytotoxicity in $\mathrm{N} 2 \mathrm{~A}$ cells treated with LPS and/ or LPS + P (10 mM). Data are expressed as mean \pm SEM, analyzed by ANOVA post hoc Dunnett and Newman-Keuls multiple comparison tests. $* * p<0.01 ; * * * p<0.001$ control
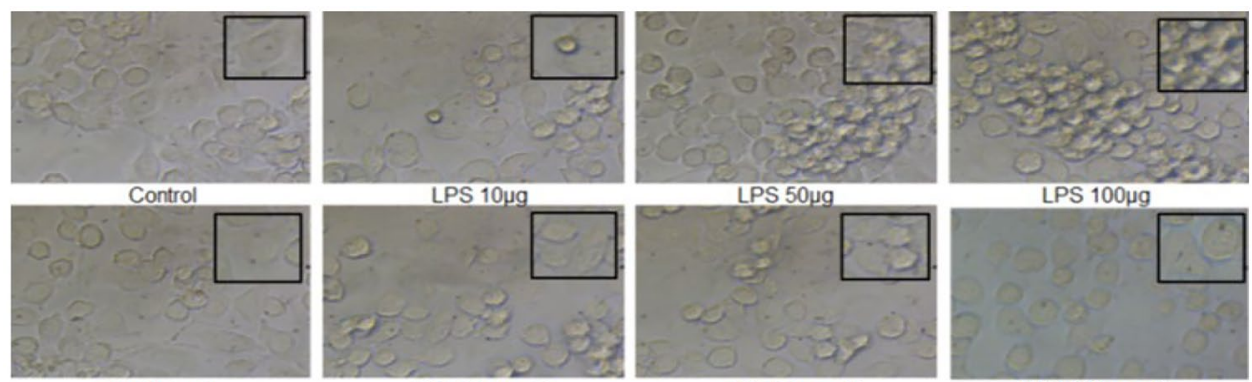

LPS $10 \mu g+P$

LPS 50 $\mu \mathrm{g}+\mathrm{P}$

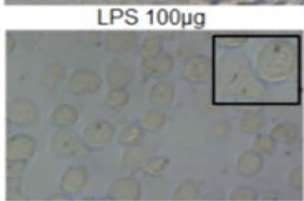

LPS $100 \mu g+P$ vs. LPS treated; ${ }^{\# \#} p<0.001$ LPS treated vs. LPS $+\mathrm{P}$ treated (C-control)

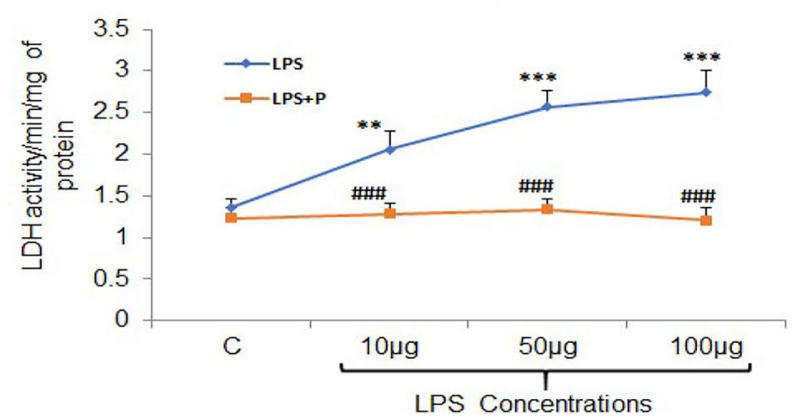

Publisher's Note Springer Nature remains neutral with regard to jurisdictional claims in published maps and institutional affiliations.

The original article can be found online at https://doi.org/10.1007/ s12640-018-9878-2.

Sarika Singh

ssj3010@gmail.com

1 Toxicology Division, CSIR-Central Drug Research Institute, Lucknow, Uttar Pradesh 226031, India
Pharmacokinetics \& Metabolism division CSIR-Central Drug Research Institute, Lucknow, U.P. 226031, India

3 Department of Biochemistry and Biophysics, Helen Diller Comprehensive Cancer Center, University of California, San Francisco, USA 